\title{
Isolated Wired and Wireless Battery Charger with Integrated Boost Converter for PEV Applications
}

\author{
M. Chinthavali, O. C. Onar, S. L. Campbell, and L. M. Tolbert \\ Power Electronics and Electric Machinery Group, Oak Ridge National Laboratory, Oak Ridge, TN 37831 \\ chinthavalim@ornl.gov, campbells1@ornl.gov, onaroc@ornl.gov, tolbertlm@ornl.gov
}

\begin{abstract}
Integrated charger topologies that have been researched so far are with the dc-dc converters and the charging functionality usually have no isolation in the system. Isolation is an important feature that is required for user interface systems that have grid connections and therefore is a major limitation that needs to be addressed along with the integrated functionality. This study features a unique way of combining the wired and wireless charging functionalities with vehicle side boost converter integration and maintaining the isolation to provide the best solution to the plug-in electric vehicle (PEV) users. The new performance of the proposed architecture is presented for wired and wireless charging options at different power levels.
\end{abstract}

Keywords-wireless power transfer, on-board charger, integrated charger, boost converter, PEV charger.

\section{INTRODUCTION}

There are several original equipment manufacturer (OEM) companies that have already deployed the on-board chargers in EVs and plug-in electric vehicles (PEV) to commercial markets. In addition, some tier-one suppliers offer after-market plug-in conversion kits for hybrid electric vehicles (HEVs). These chargers come with a plug-in interface located inside the vehicle, but need a charging station to plug into. While this is a viable option, there are several drawbacks associated with such systems. The power levels that can be achieved for charging are limited as the weight and volume are big constraints; hence the charging times are usually long. With an off-board charger, higher power levels can be achieved and this is proven to be a faster charging option. However, both the on-board and offboard chargers featuring plug-in options inherently pose a danger of electric shock. Additionally, depending on the size and rating of the charger, they are heavy and inconvenient.

These challenges can be addressed by implementing wireless power transfer (WPT) technology. WPT is becoming established as a safe, convenient and flexible charging method for PEVs. Along with convenience, one aspect of the charging technology that needs to be addressed is the cost of the charger. Integrated topologies can provide substantial cost benefits by utilizing components with different functionalities.

This manuscript has been authored by the Oak Ridge National Laboratory operated by the UT-Battelle, LLC under Contract No. DE-AC05-00OR22725 with the U.S. Department of Energy. The United States Government retains and the publisher, by accepting the article for publication, acknowledges that the United States Government retains a non-exclusive, paid-up, irrevocable, world-wide license to publish or reproduce the published form of this manuscript, or allow others to do so, for United States Government purposes. The Department of Energy will provide public access to these results of federally sponsored research in accordance with the DOE Public Access Plan (http://energy.gov/downloads/doe-public-access-plan).
Vehicle charging and vehicle traction drive components can be integrated for multi-functional operations, as these functions are currently operating independently. For instance, while the vehicle is parked, the hardware that is available from the traction drive can be used for charging. On the other hand, integrated topologies also need to have the same isolation as the conventional chargers. This adds complexity to the system controls and the hardware as well. In addition to the complexities, the other challenge for integrated topologies is the total system efficiency. The major challenge in charging systems is the ultimate goal of achieving efficiencies greater than $85 \%$ from the wall outlet to the vehicle battery. At present, being "on par" with traditional charging implies $85 \%$ to $90 \%$ overall efficiency between the grid connection and the vehicle battery pack. In addition, having the wired (plug-in) and wireless charging systems available at the same time is crucial, especially before the transition is made to all wireless chargers. Most users would prefer to have both functionalities and the availability conditions would determine the usage.

Based on the literature survey, it is evident that the topologies with integrated $\mathrm{dc}-\mathrm{dc}$ converter and charging functionality have no isolation in the system. Isolation is an important feature that is required for user interface systems that have grid connections to prevent potential shock hazards and also ground faults; therefore, it is a major limitation that needs to be addressed along with the integrated functionality. There are two solutions that can be used to essentially address this issue. One is a traditional high frequency (HF) isolation transformer that can be added to the integrated system on board. However, this adds an additional power stage, complexity, component cost, and weight to the car, and defeats the purpose of the integrated functionality. The other solution that can be utilized is an inherently isolated wireless charging system that can provide the required isolation from the grid. The WPT system has a huge benefit compared to other systems in terms of the component count that can be added to the car. The secondary system in the car can be as simple as a LC resonant coil with a rectifier and a filter capacitor. The rest of the system is located on the grid side stationary unit that has several stages of power conversion. Both the above-mentioned solutions are very attractive and have their pros and cons. However, there is a unique way of combining these functionalities and providing the best solution to PEV users. The topology proposed in this study integrates the wireless charging system and the boost converter of the traction drive system. This architecture has two levels of isolation with multifunctional operation flexibility, such as charging and boosting function. After system descriptions, the proposed system is tested for both wired and wireless operating modes 
and performance characteristics are given. The overall system architecture and the details of the design trade-offs compared to an on-board charging system are discussed in the following sections.

\section{ON-BOARD CHARGERS FOR PLUG-IN VEHICLES INTEGRATED WITH TRACTION DRIVE}

PEV chargers can be broadly divided into two categories: on-board and off-board chargers. The on-board chargers are typically limited in power, up to Level-1 charging, because of size and weight constraints. Some on-board chargers are equipped with Level-2 connection; however, they can only accept $3.3 \mathrm{~kW}$ maximum such as in Chevy Volt and Nissan Leaf. Some PHEVs, such as Prius Plug-in, can accept Level-2 charging at a smaller power rating; i.e., $2.1 \mathrm{~kW}$ nominal. The on-board chargers have limited charging power capability, with long charging times and are not typically suitable for opportunity charging and long range EVs. However, PEV traction drive power electronics can handle at least 25-30 kilowatts $(\mathrm{kW})$. This provides an opportunity for integrated charger concepts, which can reduce the weight, volume, and cost by integrating components in a traction drive system. The integrated charger topologies can be classified into two broad categories based on the location of the integration in a traction drive system. One is based on the concept of using the boost dc-dc converter and the other is using the motor(s) in the drivetrain as shown in Fig. 1. These integrated chargers are presented in several research papers [1]-[11].

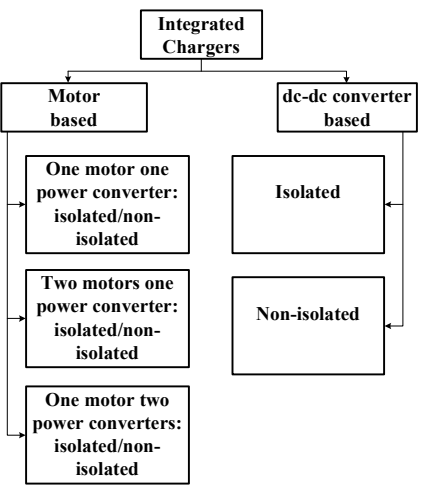

Fig. 1. Classification of the integrated charger architectures.

\section{SYSTEM DESCRIPTION}

Figure 2 illustrates the proposed integrated wireless charging architecture. The topology has five stages of power conversion from the wall to the battery in the wireless charging mode and four stages in the wired charging mode. The boost mode of operation essentially remains the same as it is in the on-road vehicles.

\section{A. Wireless Charging Mode of Operation}

Figure 3 demonstrates the circuit topology for the wireless mode of operation. Utility ac power is converted to controllable dc voltage by the active front end comprising a power factor correction (PFC) stage. Adjustable dc voltage is applied to DC bus of a HF full-bridge inverter with a controllable duty ratio. The HF stage delivers excitation current to a series tuned primary coil and the power is transferred to the secondary coil on the vehicle across the air gap. Voltage induced at the secondary is rectified, filtered, and delivered to the vehicle battery. One of the advantages of the integrated wireless charger is that the boost inductor in series with the battery pack will minimize the battery charging current ripple, and with the capacitor, it acts as a low pass filter. This feature will increase the reliability and lifetime of the battery. WPT applications may require inclusion of a HF transformer to provide electrical isolation of the WPT primary pad and the ac grid. Isolation requirements and grid power quality are currently being discussed by the standards committee in the Society of Automotive Engineers (SAE) [12]. In addition to the isolation, the HF transformer can be utilized to step down the HF inverter output voltage that enables the inverter to be operated at high voltage and low currents and results in higher efficiencies for the system.

\section{B. Wired Charging Mode of Operation}

The HF transformer solution also provides the flexibility of using the system as a wired charger. This can be achieved by simply using a relay system that can be manually operated to disconnect the resonant coil system and connect the output of the HF transformer to the on-board section of the integrated charger system. The wired charging mode of operation utilizes the four of power stages, excluding the coils. This mode of operation enables the EV users to use the plug-in charger wherever there is no wireless charging option. The efficiency of the system is compared to the wireless mode of operation in following sections. Figure 4 shows the circuit topology for the wired mode of operation.

\section{Boost Mode of Operation}

The boost mode operation simply utilizes a single stage switch and a diode combined with an inductor designed for boost operation. The wireless and wired charging power stages are completely isolated by using the relays in the system. This topology is completely based on the two independent functions of the integrated systems, (1) charging and (2) boost, which do not require simultaneous operation as in Fig. 5.

\section{DeSign AND Simulation OF The Proposed System}

\section{A. Design considerations for WPT based systems}

There are certain design constraints for this particular system and also in general for the WPT based charging systems that will determine the design parameters for each power conversion stage and the components associated with them. The major fixed constraints are the ac input line voltage and current, output load conditions and the size of the resonant coils. The ac line voltage and current will determine the overall power rating of the entire WPT system as well as the power that will be available for the load. Similar to the on-board chargers, the charging power level can be categorized as WPT Level-1, 2 and 3. The output load condition for the automotive applications is determined by the battery voltage range. Once the input voltage and battery voltage range are determined for a given design, the maximum current through the resonant coil system can be determined. The other critical independent parameter is the size of the coil and the inductance that is associated with it. 


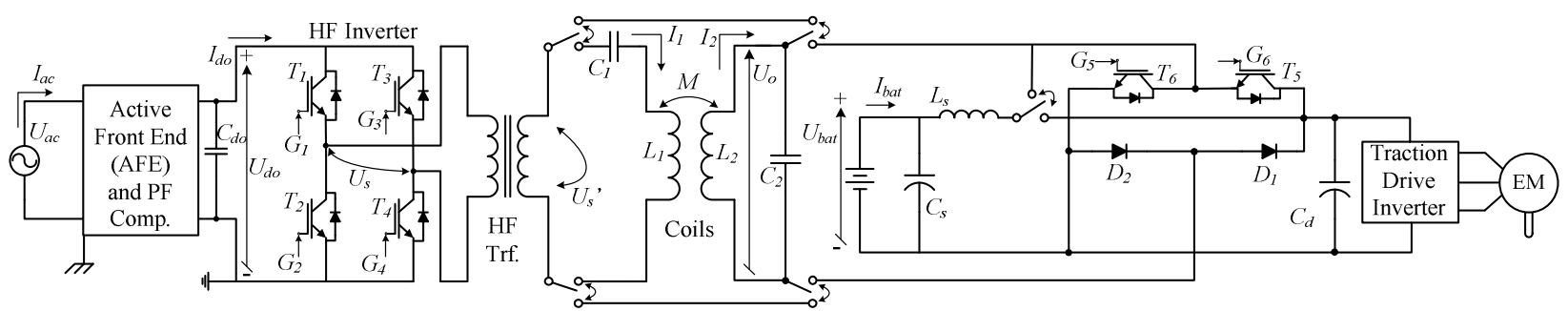

Fig. 2. Circuit architecture of the proposed integrated charger.

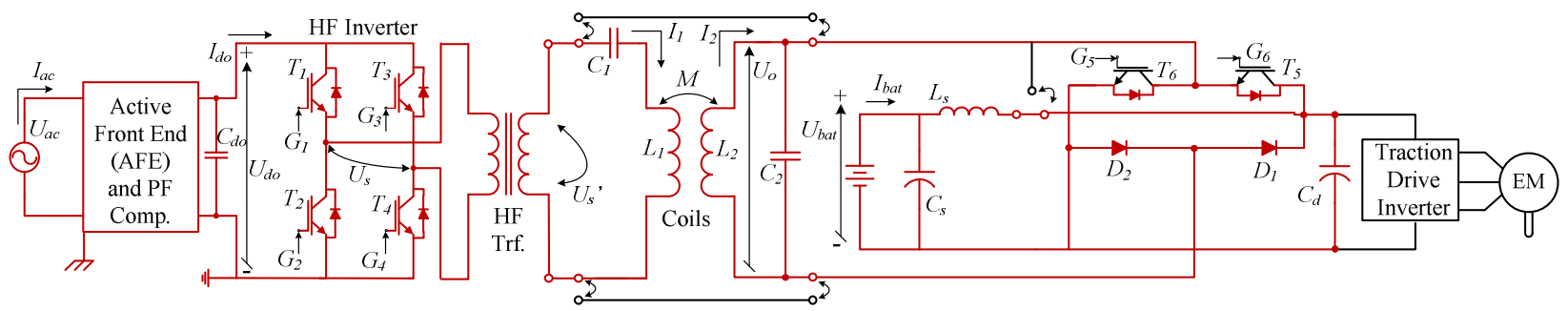

Fig. 3. Circuit configuration for wireless operation mode.

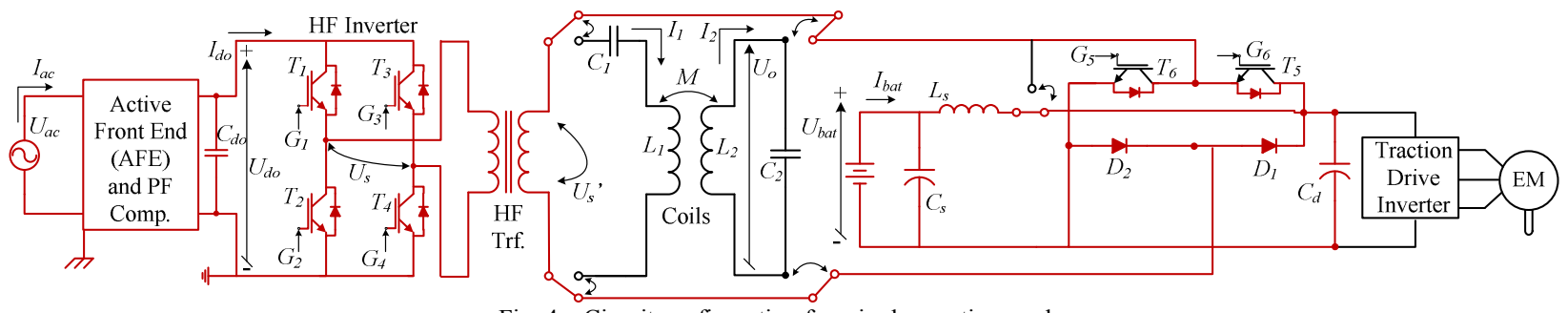

Fig. 4. Circuit configuration for wired operation mode.

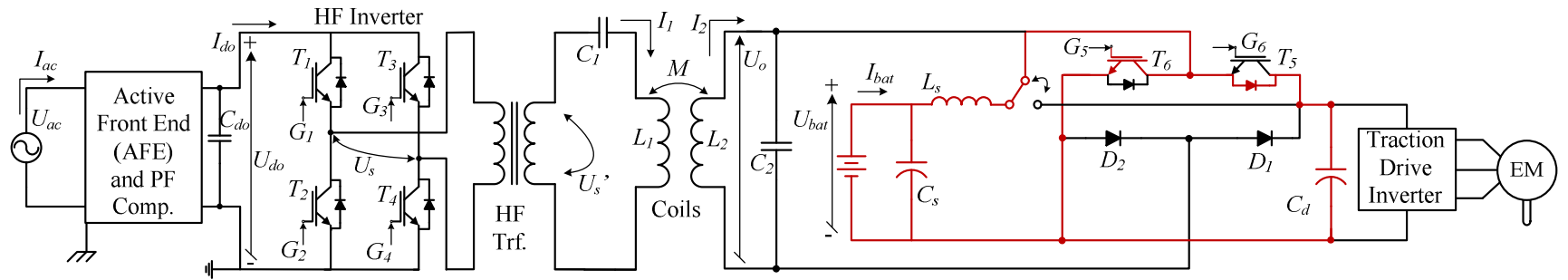

Fig. 5. Circuit configuration for boost mode of operation.

For a given distance between the coils, the diameter of the coils can be calculated. Typically, coil diameter should be two times larger than the transfer distance [13]. After the diameter and current is determined, the appropriate wire size is selected. Then, based on the physical dimensions, and the inductance needed, the number of turns in the coils is calculated. The other critical parameters that have significant effects on the system efficiency are the magnetic field and the electric field at the operating frequency of the resonant system. Once these above mentioned design parameters are fixed, then the resonant compensation capacitors can be determined. The secondary compensation network needs to be designed for the given frequency and then the primary compensation can be tuned based on the load impedance and the coupling coefficient $k$. The ideal operating condition for the compensation network is the frequency at which the imaginary power is zero.

Another design feature that will also influence the other power stages and overall control system architecture is the natural voltage gain of the resonant tank system for a given operating frequency range. This gain will impose the voltage input requirements at the input of the resonant tank. This gain curve is different for different coil designs, tuning configurations, the coil topology, and the quality factor of the resonance. The voltage requirements will restrict the duty cycle of operation of the HF inverter and will eventually affect the reactive power requirements. Given the overall general guidelines as discussed in this section, the following choices were made for the proposed systems.

\section{1) Resonant coil tuning configuration}

A series or parallel tuning can be used to form the resonant. The series configuration at the primary will result in high currents and is a current controlled network. The secondary tuning, also determines the sharpness of the frequency versus power characteristics of the system. The series-parallel provides single peak in power transfer and single transition of input power factor. Based on a study from Oak Ridge National Laboratory (ORNL), it was shown that with series-series tuning, the peak power range is broader for a given frequency band and then drops outside of the band [13], [14]. In addition, with series-series tuning, primary reactive 
power is higher compared to other configurations. Also, the ORNL study revealed the series-parallel configuration has wider skirts in the power versus frequency resonance curve and does not have a sudden drop in power compared to the series-series configuration. This allows for more degrees of freedom in control and in actual hardware implementation.

\section{2) Active front-end rectifier topology}

Since a HF transformer is used which can step-down the voltage, a single-stage active rectifier with voltage boosting functionality is chosen for the proposed system. The active boost rectifier allows for regulating and controlling the dc input to the inverter. The other reason for boost rectification is because the efficiency of the system is dependent on the primary side dc link voltage as the inverter losses are less for lower currents and higher voltages. The ac boost rectifier utilizes a single phase leg with active switches and a diode leg to minimize the losses during the boost operation as shown in Fig. 6. A single switch is used during the positive half cycle and another in the negative half cycle [15]. The single stage boost converter has a small ac input capacitor and a boost inductor at the input of the rectifier.

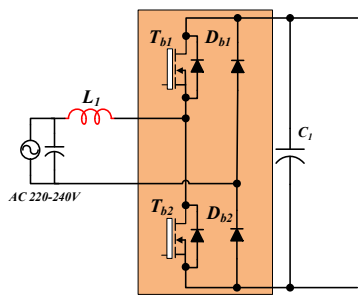

Fig. 6. Single-stage boost active rectifier converter for WPT system.

\section{3) High frequency transformer}

The parameters for this HF transformer are determined based on the amount of voltage that needs to be stepped down for a given input AC voltage. Primary and secondary side current ratings can be determined based on the power and turns-ratio. Based on the frequency of operation, the core size and material can be determined. The other critical parameter is the total leakage inductance of the transformer that indirectly affects the resonant frequency of the system. Since the transformer is tightly coupled, leakage inductance is relatively smaller and is in series with the primary coil inductance [14].

\section{Simulations Of THE PROPOSED SySTEM}

A simulation model was built using PSIM which is an implementation of the overall system depicted in Fig. 2. The resonant coil system is modeled as a coupled inductor model. The HF transformer is modeled as an ideal transformer with series leakage inductance. The magnetizing branch inductance, $L_{m}$, is assumed to be too high for this highly coupled core based HF transformer. The control system that was implemented for this model is discussed in detail in [15]. The parameters used for the simulation are given in Table I. The inductances of the coils were obtained from the measured values of the prototypes built. The turns-ratio of the transformer is designed to be 10:2. This was enough to step the voltage of the inverter output and accommodate the designed resonant system gain of 3.1 at 22 $\mathrm{kHz}$.

\section{A. Wireless Mode}

Figures 7 and 8 show the complete system response to a $6.6 \mathrm{~kW}$ charge power request at the battery terminals. In order to supply this amount of power, the control system automatically boosts and regulates the dc-link voltage around $\sim 450 \mathrm{~V}$. The current that the controlled rectifier draws from the grid is in phase with the grid voltage with close to unity power factor. The reference and actual measured grid current variations are plotted in order to demonstrate the performance of the current control loop. The inverter output voltage and the primary coil voltage in Fig. 8 (a) and (b) show the impact of the total transformer leakage inductance. In Fig. 8, battery voltage and current with detailed zoom with the resulting ripples are shown in addition to the battery power $(\sim 6.6 \mathrm{~kW})$. The input power is around $7.65 \mathrm{~kW}$ and the total efficiency (ac-dc) is $\sim 86.2 \%$.

TABLE I. ANALYTICAL AND SimUlation MODEL PARAMETERS

\begin{tabular}{|c|c|c|c|}
\hline Parameter & \multicolumn{1}{|c|}{$\boldsymbol{S y m b o l}$} & Value & Unit \\
\hline \hline AC input voltage & $\boldsymbol{U}_{\boldsymbol{a c}}$ & 220 & {$\left[\mathrm{~V}_{\mathrm{ac}}\right]$} \\
\hline DC link voltage & $\boldsymbol{U}_{\boldsymbol{d} \boldsymbol{o}}$ & $350-600$ (controlled) & {$\left[\mathrm{V}_{\mathrm{dc}}\right]$} \\
\hline Primary tuning capacitor & $\boldsymbol{C}_{\boldsymbol{I}}$ & 0.45 & {$[\mu \mathrm{F}]$} \\
\hline Primary coil inductance & $\boldsymbol{L}_{\boldsymbol{I}}$ & 115.79 & {$[\mu \mathrm{H}]$} \\
\hline$L_{\boldsymbol{l}}$ internal resistance & $\boldsymbol{R}_{\boldsymbol{L} \boldsymbol{1}}$ & 122.7 & {$[\mathrm{~m} \Omega]$} \\
\hline Secondary coil inductance & $\boldsymbol{L}_{\boldsymbol{2}}$ & 132.6 & {$[\mu \mathrm{H}]$} \\
\hline$L_{2}$ internal resistance & $\boldsymbol{R}_{\boldsymbol{L} \boldsymbol{}}$ & 150.8 & {$[\mathrm{~m} \Omega]$} \\
\hline Secondary tuning capacitor & $\boldsymbol{C}_{\boldsymbol{2}}$ & 0.40 & {$[\mu \mathrm{F}]$} \\
\hline Coupling factor & $\boldsymbol{k}$ & 0.23 & $\#$ \\
\hline Distance between the coils & $\boldsymbol{z}$ & 160 & {$[\mathrm{~mm}]$} \\
\hline Filtering capacitor & $\boldsymbol{C}_{\boldsymbol{o}}$ & 680 & {$[\mu \mathrm{F}]$} \\
\hline Battery nominal voltage & $\boldsymbol{U}_{\boldsymbol{b}}$ & 310 & {$\left[\mathrm{~V}_{\mathrm{dc}}\right]$} \\
\hline Battery target power & $\boldsymbol{P}_{\boldsymbol{b}}$ & 6600 & {$[\mathrm{~W}]$} \\
\hline
\end{tabular}

Input AC line current Reference current AFE

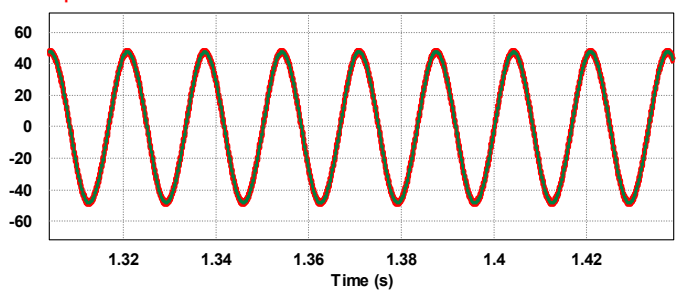

Input AC line voltage Input AC line current

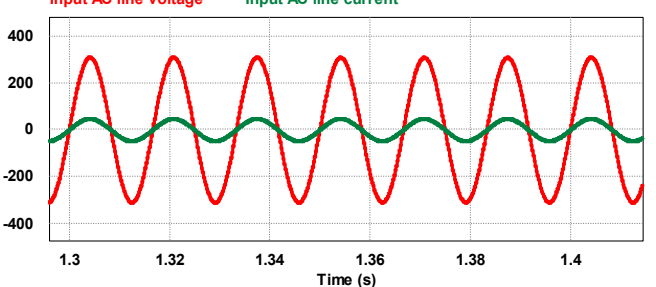

(a)

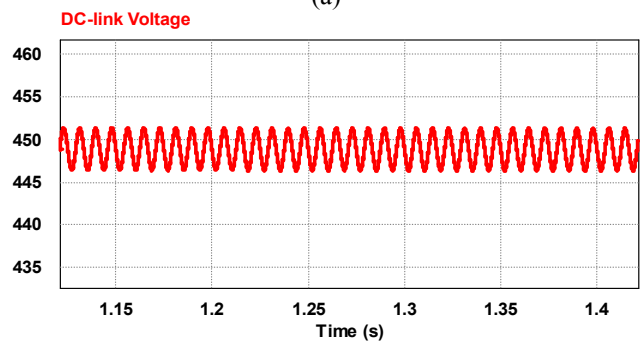

(b)

Fig. 7. Simulation result: AC line voltage and current (a) and the boosted DC link voltage (b). 


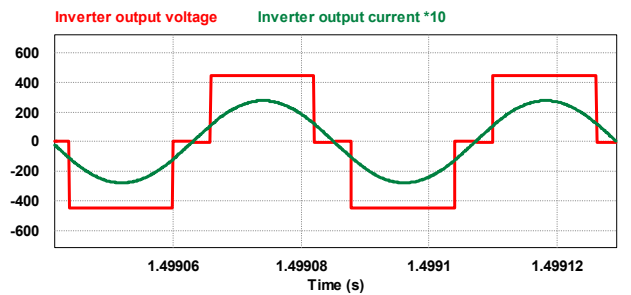

(a)

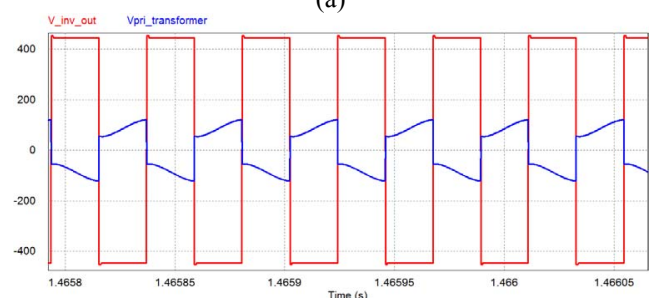

(b)
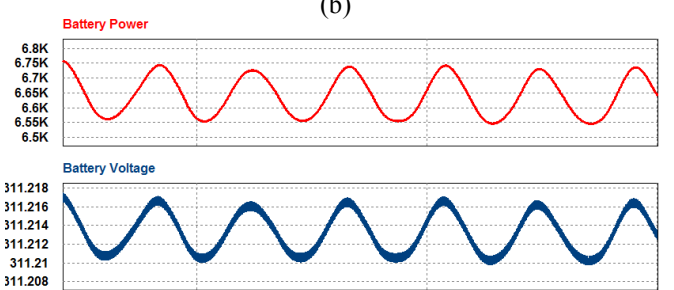

$$
\text { Battery Current }
$$

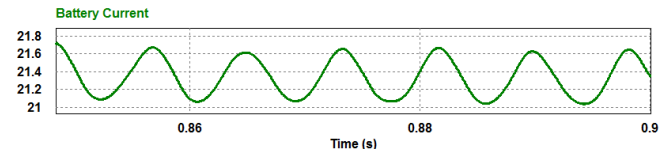

(c)

Fig. 8. Simulation results: Inverter output voltage and current (a), inverter output voltage and primary coil voltage (transformer output) (a), vehicle battery power, voltage and current (c) variations.

\section{B. Wired Mode}

The wired (plug-in charging) mode was simulated without the resonant tank and all the components parameters are kept the same. Since there is no resonant voltage gain, transformer parameters with 8:5 turns-ratio is used which would also work with wireless mode. The control system strategy for the wired mode is same with the wireless mode. Near unity power factor was achieved with the wired mode as well. The reference and actual measured grid current are plotted in order to demonstrate the performance of the current control loop as shown in Fig. 9 whereas Fig. 10 shows the DC link voltage without coils.

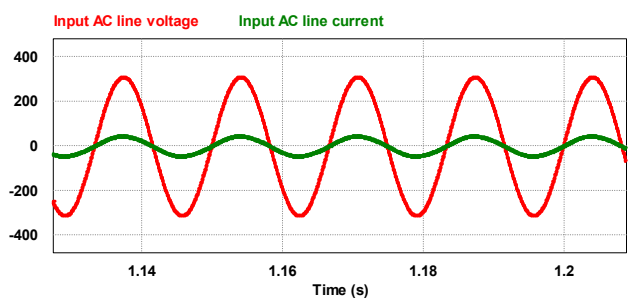

Fig. 9. Wired mode simulation results showing grid voltage and current.

It is seen from Fig. 10 that the rectified boosted voltage is higher than the wireless mode. This is due to the fact that system requires higher voltage since there is no resonating circuit after the inverter and therefore a higher voltage level is needed for the same level of power transfer to the load. The inverter and the transformer output voltages and currents are shown in Fig. 11. Finally, Fig. 12 shows the amount of power transfer to the load side $(\sim 6.6 \mathrm{~kW})$. The input power is around $7.65 \mathrm{~kW}$. Again this verifies that the closed loop control system is operating as designed and the output power is regulated to the reference value.

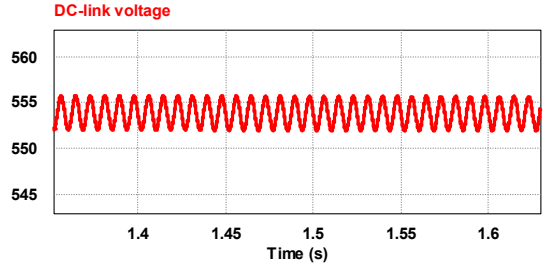

Fig. 10. DC link voltage in wired mode of operation.
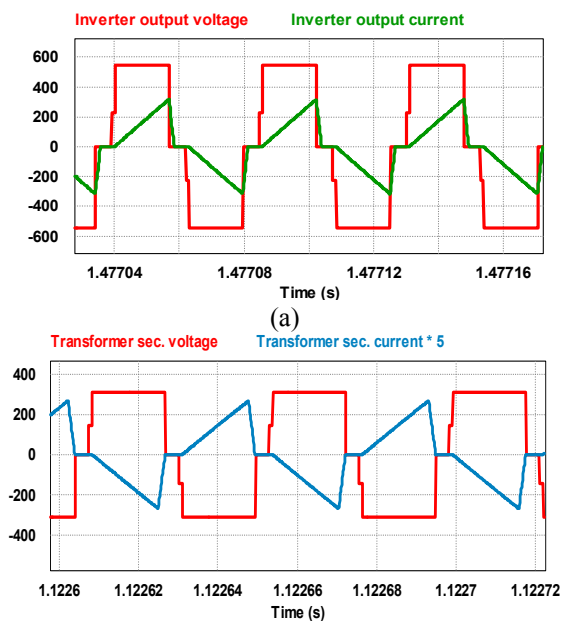

(b)

Fig. 11. Inverter output voltage and current (a) and transformer output voltage and current (b).
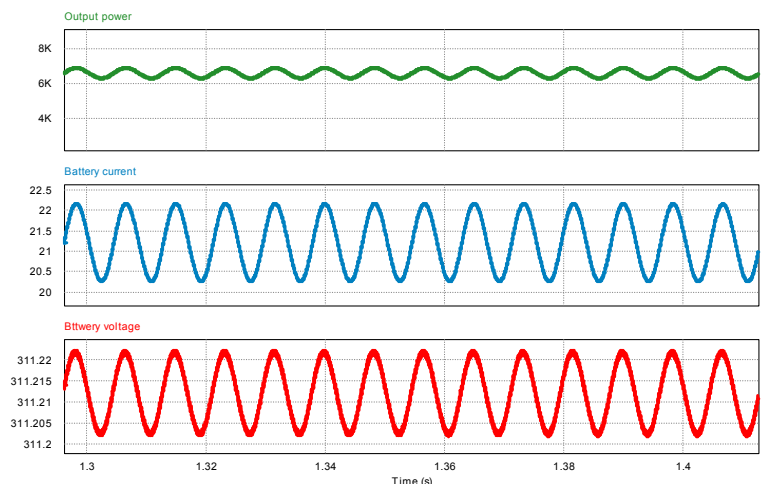

Fig. 12. Battery power, current, and voltage under wired mode.

\section{EXPERIMENTAL TEST SETUP AND RESUltS}

This section details the design and implementation of subsystems of the proposed topology.

\section{A. Design and Implementation of the Magnetics}

The details of the coupling coils design are presented in [13]-[15]. A similar design procedure was followed and the coil parameters are summarized in Table II. The coil prototypes are shown in Fig. 13. 
TABLE II. COUPLING COIL PARAMETERS

\begin{tabular}{|c|c|c|c|}
\hline Parameter/Dimensions & Primary & Secondary & Unit \\
\hline a (inside) dimension & $640-196=444$ & $616-126=490$ & {$[\mathrm{~mm}]$} \\
\hline $\mathrm{b}$ (outside) dimension & 640 & 616 & {$[\mathrm{~mm}]$} \\
\hline$r_{e q}$ (circ. coil equiv.) & 300.7 & 310 & {$[\mathrm{~mm}]$} \\
\hline$N_{c}$ (number of turns) & 9 & 9 & $\#$ \\
\hline AWG & 2 & 6 & $\#$ \\
\hline
\end{tabular}

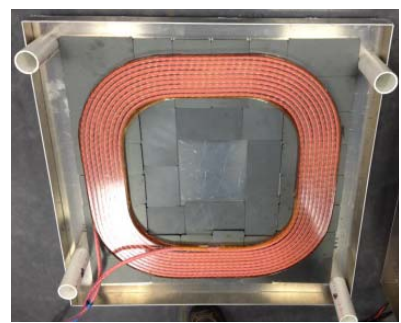

Fig. 13. Primary and secondary WPT coils.

For the HF transformer, 8 of the Ferroxcube 3C94 low-loss $\mathrm{MnZn}$ ferrite ring core stack were used while the primary and secondary windings are wound on the same core. The primary (input) side of the transformer is connected to the HF power inverter H-bridge output whereas the secondary side is attached to the coil and tuning capacitor network. The transformer parameters are presented in Table III and the prototype is shown in Fig. 14.

TABLE III. HF TRANSFORMER PARAMETERS

\begin{tabular}{|c||c|c|}
\hline \multicolumn{1}{|c||}{ Parameter } & Value & Unit \\
\hline \hline Primary turns & 10 & $\#$ \\
\hline Secondary turns & 2 & $\#$ \\
\hline Primary leakage inductance & 23.60 & {$[\mu \mathrm{H}]$} \\
\hline Secondary leakage inductance & 1.14 & {$[\mu \mathrm{H}]$} \\
\hline Mutual inductance & 3.87 & {$[\mathrm{mH}]$} \\
\hline Coupling coefficient & 0.9946 & $\#$ \\
\hline Primary resistance $@ 22 \mathrm{kHz}$ & 31.5 & {$[\mathrm{~m} \Omega]$} \\
\hline Secondary resistance $@ 22 \mathrm{kHz}$ & 1.14 & {$[\mathrm{~m} \Omega]$} \\
\hline \hline
\end{tabular}

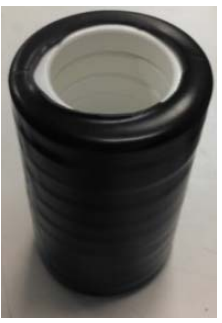

(a)

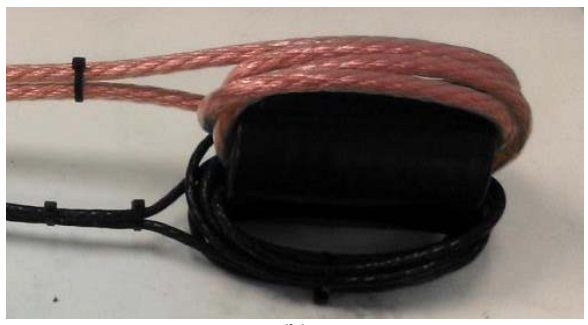

(b)
Fig. 14. HF transformer core (a) and the final built (b).

\section{B. Design and Implementation of the Power Stage}

The active front-end rectifier was built using the commercially available 1200V, 100A SiC MOSFET-based phase-leg modules. The $\mathrm{SiC}$ modules were used because of the high voltage in the dc-link. The details of the design are shown in [15]. The HF inverter was built with $600 \mathrm{~V}, 600 \mathrm{~A}$ dual Powerex Intellimod IGBTs in an H-bridge arrangement. The inverter and the PFC were cooled using a water and ethylene glycol mix and the receiver side rectifier was cooled using fan based heat sink. The control system of the inverter is implemented within a TMS320F28335PGFA DSP module from Texas Instruments. The primary side (grid-side) power stage is given in Fig. 15.

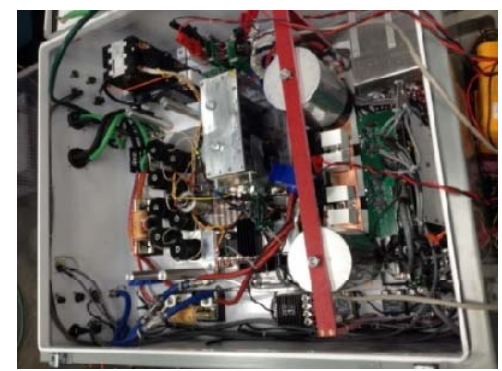

Fig. 15. PFC converter integrated with the high frequency power inverter and enclosed in the stationary box.

\section{Experimental Setup and Tests}

The experimental setup of the system with SiC-based active-rectifier including primary (bottom) and secondary coil (top) and in the background the HF transformer, resonant tuning capacitors and vehicle side rectifier with a small filter capacitor are shown in Fig. 16 (a) and (b).

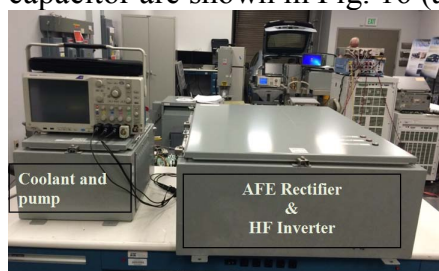

(a)

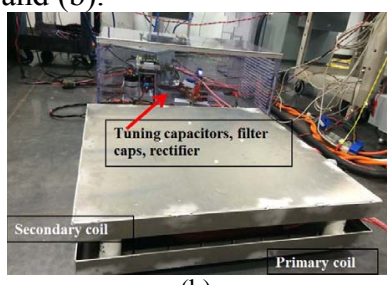

(b)
Fig. 16. Grid side unit enclosed in a box with the cooler (a) and primary and secondary coils, tuning capacitors, and vehicle side rectifier and filter.

\section{1) Wireless Mode of Operation Experimental Results}

The experimental set-up is used to evaluate the wireless mode first. The transformer is wound for a turns-ratio of 10:2 as per the design and the load voltage was set to $311 \mathrm{~V}_{\mathrm{dc}}$. The ac input voltage is $220 \mathrm{~V}_{\mathrm{rms}}$. The desired $6.52 \mathrm{~kW}$ power transfer to the vehicle battery for an input power of $7.67 \mathrm{~kW}$ to the system was achieved. This power level corresponds to $\sim 85.05 \%$ overall efficiency from AC grid to the vehicle battery terminals. The voltage and current waveforms for the AC input and DC link to the inverter are given in Fig. 17 whereas the inverter, transformer, coil, and rectifier output waveforms are given in Fig. 18. The detailed stage-by-stage power of the system is illustrated in Fig. 19 (highlighted in green).

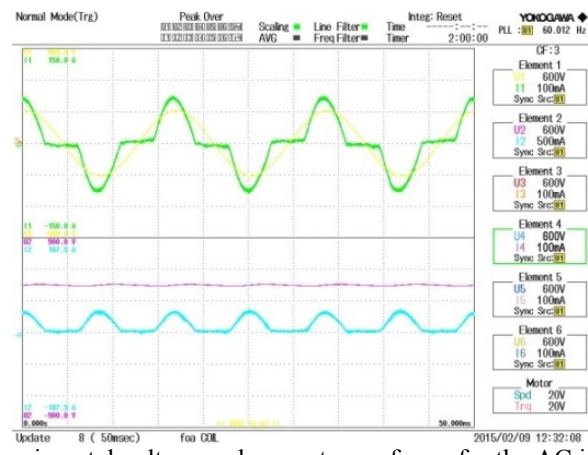

Fig. 17. Experimental voltage and current waveforms for the AC input and the DC link to the inverter. 


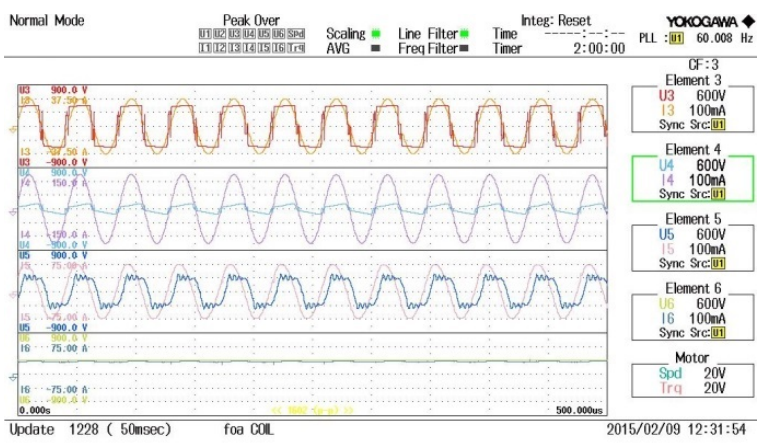

Fig. 18. Experimental voltage and current waveforms for the inverter, transformer, coil, and rectifier outputs.

As can be observed from experimental results, the dc-link voltage is $453.9 \mathrm{~V}_{\mathrm{dc}}$ which closely matches with the simulated value of $452 \mathrm{~V}_{\mathrm{dc}}$ for the same system parameters. One more important parameter is the leakage inductance of the transformer and its effect on the turns-ratio. The effect of the transformer leakage inductance can be observed in the waveforms of the transformer secondary voltage as shown in Fig. 18. The value of leakage inductance is $45 \mu \mathrm{H}$ and the current is around $\sim 18 \mathrm{~A}_{\mathrm{rms}}$. The inductive reactance is dependent on the resonant frequency. So for higher frequencies the voltage drop could be even higher which makes the impact of the transformer parameters even more critical.

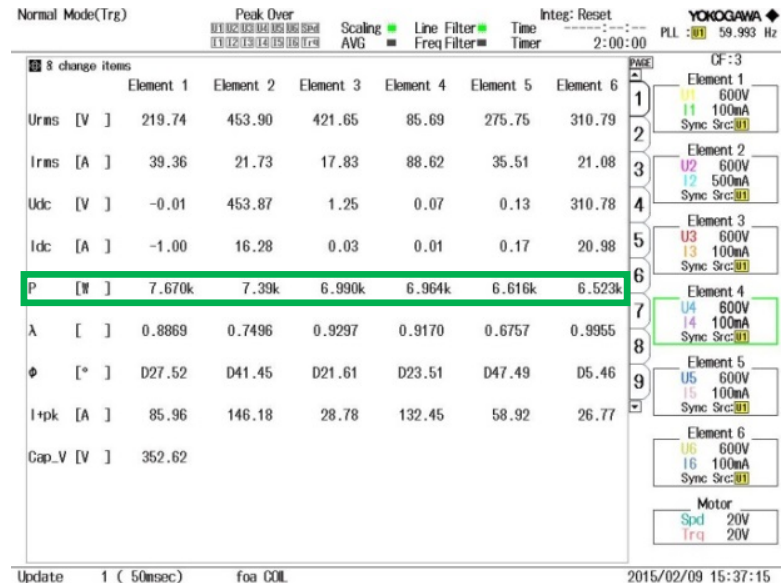

Fig. 19. The stage-by-stage power of the system after each power conversion

Stage by stage cascaded efficiencies including the end-to-end and dc-to-dc efficiency are given in Fig. 20.

$$
\begin{aligned}
& \begin{array}{r}
\text { End-to-end } \\
\stackrel{P_{\text {in }}}{\longrightarrow} 85.05 \% \stackrel{P_{\text {out }}}{\longrightarrow}
\end{array} \\
& \begin{aligned}
& \text { Dc-to-Dc } \\
\longrightarrow & 88.25 \%
\end{aligned}
\end{aligned}
$$

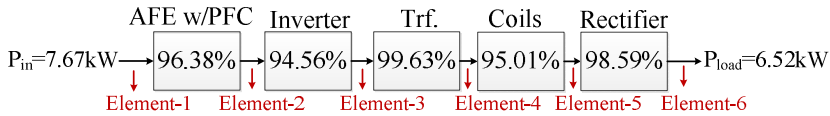

Fig. 20. Stage-by-stage cascaded efficiency of the proposed integrated charger in wireless charging mode.

The proposed system is also tested at different power levels; i.e., at $1.06,2.34,3.15,3.96,4.73,5.48$, and $6.526 \mathrm{~kW}$ and the efficiency of the each power conversion stage is obtained with respect to the different levels of the charging power delivered to the load. The power vs. efficiency curves of the PFC, inverter, coils, and the rectifier are presented in Fig. 21 (a) and (b).

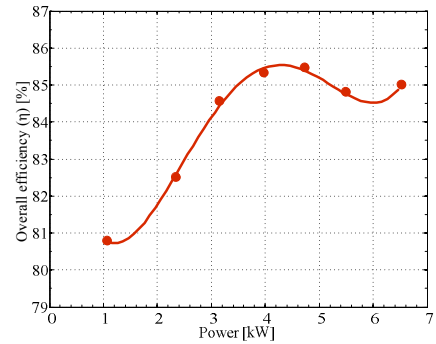

(a)

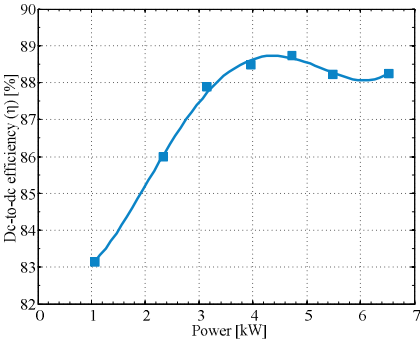

(b)
Fig. 21. System efficiency at different power transfer levels for wireless operation: Overal efficiency (a) and dc-to-dc efficiency (b).

\section{2) Wired Mode of Operation Experimental Results}

The experimental set-up that is used to evaluate the wireless mode is modified to the wired mode test by changing the transformer and removing the resonant network based on the design discussed in the previous chapter. The transformer is wound for a turns-ratio of 8:5 as per the design and the load voltage is set to $311 \mathrm{~V}_{\mathrm{dc}}$. The ac input voltage is set to 220 $\mathrm{V}_{\mathrm{rms}}$ and the corresponding power at stage is recorded. The dclink boost voltage is $549.5 \mathrm{~V}_{\mathrm{dc}}$ which closely matches with the simulated value of $554 \mathrm{~V}_{\mathrm{dc}}$ for the same system parameters. Unlike the wireless mode of operation the effect is leakage inductance is negligible. The load power is recorded $\sim 6.4 \mathrm{~kW}$ required an input power of $7.6 \mathrm{~kW}$. This power level corresponds to $\sim 84.06 \%$ overall efficiency from AC grid to the vehicle battery terminals. The detailed stage-by-stage power output of the system is presented in Fig. 22. The voltage and current waveforms for the AC input and DC link to the inverter are given in Fig. 23, whereas the inverter, transformer, coil, and rectifier output waveforms are given in Fig. 24. In Fig. 25, dc-to-dc (from inverter input to the vehicle battery) and the overall end-to-end efficiency values of each power conversion stages are shown. The proposed system is also tested at different power levels; i.e., 1.46, 2.32, 3.14, 4.57, 5.33 , and $6.38 \mathrm{~kW}$ and the efficiency of the each power conversion stage is obtained with respect to the different levels of the charging power delivered to the load, as shown in Fig. 26 (a) and (b).

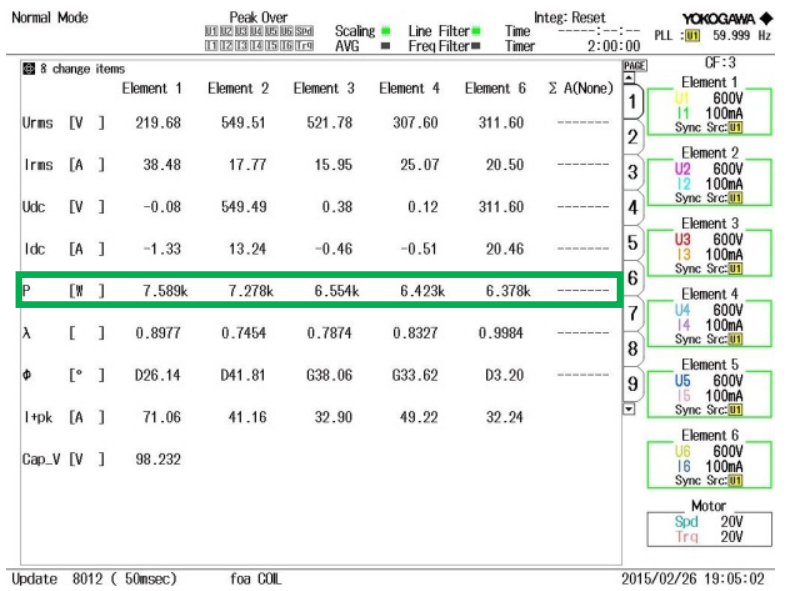

Fig. 22. Detailed stage-by-stage powers of the wired charging operation mode. 


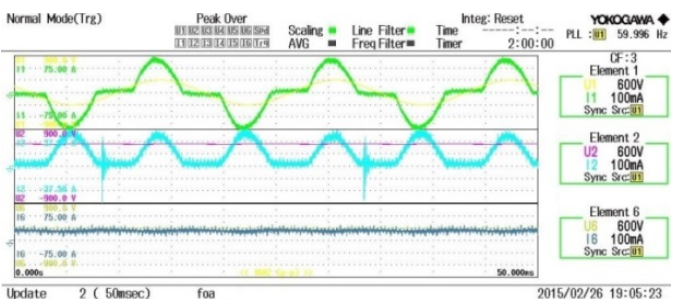

Fig. 23. Experimental voltage and current waveforms for the $\mathrm{AC}$ input and DC link to the inverter.

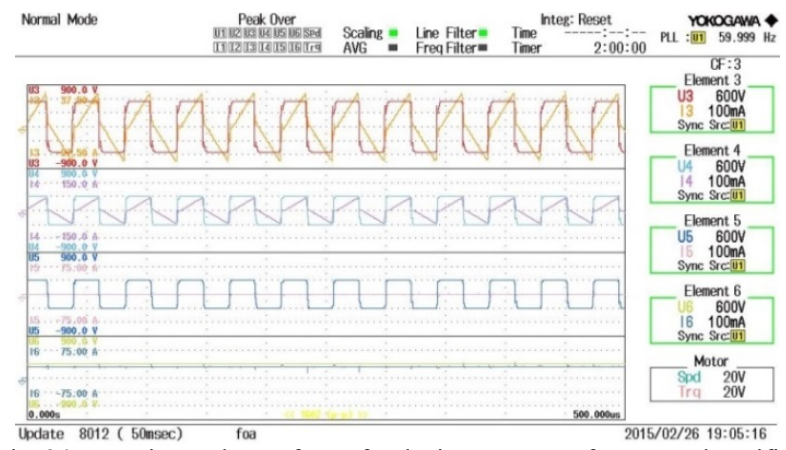

Fig. 24. Experimental waveforms for the inverter, transformer, and rectifier outputs.

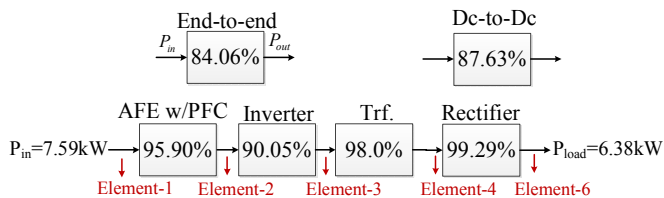

Fig. 25. Experimental stage by stage efficiencies for the wired charging mode.

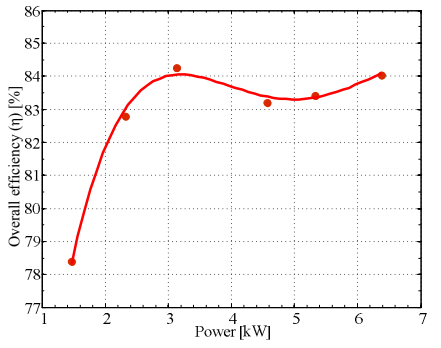

(a)

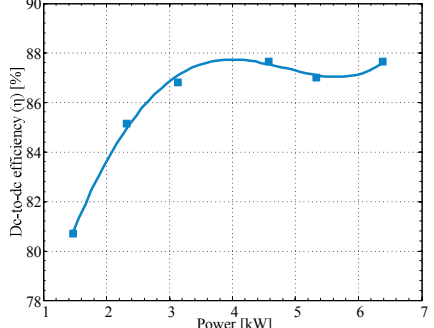

(b)
Fig. 26. System efficiency at different power transfer levels for wired operation: Overal efficiency (a) and dc-to-dc efficiency (b).

\section{CONCLUSIONS}

A new integrated charger topology with wired and wireless charging and boost function is presented. According to the experimental test results, the end-to-end and dc-to-dc efficiencies of the system are $85.05 \%$ and $88.25 \%$ for wireless charging mode whereas these efficiency values are $84.06 \%$ and $87.63 \%$ for the wired charging mode of operation. In order to have the system interoperable with both wired and wireless charging modes, the transformer turns ratio had to be changed to 8:5 instead of 10:2 since the wired option does not have the natural voltage gain effect of the resonant wireless charging. In this case, the same transformer turns ratio can provide both wired and wireless charging functionalities without any additional changes in the system but with slight efficiency reduction due to the higher current levels that the primary circuit had to deliver. The proposed integrated charger offers both wired and wireless charging capability with isolation. Moreover, the proposed approach removes most of the charging components from vehicle to off-board; therefore, onvehicle components have much less size, volume, and cost as compared to commercially available on-board chargers while increasing the charging power ratings.

\section{ACKNOWLEDGMENT}

Authors would like to acknowledge Cliff P. White and Larry E. Seiber for their support on power electronics and magnetics hardware development for this study.

\section{REFERENCES}

[1] D. Thimmesch, "An SCR inverter with an integral battery charger for electric vehicles," IEEE Transactions on Industry Applications, vol. IA21, no. 4, pp.1023-1029, July/August 1985.

[2] W. E. Rippel and A. G. Cocconi, "Integrated motor drive and recharge system," US Patent 5099186, March 1992.

[3] D. G. Woo, G. Y. Choe, J. Kim, B. Lee, J. Hur, G. Kang, "Comparison of integrated battery chargers for plug-in electric vehicles: Topology and control," in Proc. IEEE International Electric Machines \& Drives Conference (IEMDC), pp. 1294-1299, May 2011, Niagara Falls, CA.

[4] L. Tang and G. J. Su, "A low-cost, digitally-controlled charger for plugin hybrid electric Vehicles," in Proc., IEEE Enrg. Conv. Congress and Exposition (ECCE), pp. 3923-3929, Sept. 2009, San Jose, CA.

[5] L. De-Sousa and B. Bouchez, "Method and electric combined device for powering and charging with compensation means," International Patent WO 2010/057893 A1, 2010.

[6] S. Haghbin, "An isolated integrated charger for electric or plug-in hybrid vehicles," Thesis for The Degree of Licentiate of Engineering, Chalmers University of Technology Göteborg, Sweden, 2011.

[7] A. Bruyère, L. De Sousa, B. Bouchez, P. Sandulescu, X. Kestelyn, and E. Semail, "A Multiphase Traction/Fast-Battery-Charger Drive for Electric or Plug-in Hybrid Vehicles," in Proc. IEEE Vehicle Power and Propulsion Conference (VPPC), pp. 1-7, September 2010, Lille, France.

[8] Y. J. Lee, A. Khaligh, and A. Emadi, "Advanced integrated bidirectional ac/dc and dc/dc converter for plug-in hybrid electric vehicles," IEEE Trans. on Veh. Tech., vol. 58, no. 8, pp. 3970-3980, October 2009.

[9] D. C. Erb, O. C. Onar, and A. Khaligh, "An integrated bidirectional power electronic converter with multi-level AC-DC/DC-AC converter and non-inverted buck-boost converter for PHEVs with minimal grid level disruptions," in Proc., IEEE Vehicle Power and Propulsion Conference, pp. 1-6, September 2010, Lille, France.

[10] H. Chen, X. Wang, and A. Khaligh, "A single stage integrated bidirectional $\mathrm{ac} / \mathrm{dc}$ and $\mathrm{dc} / \mathrm{dc}$ converter for plug-in hybrid electric vehicles," in Proc., IEEE Vehicle Power and Propulsion Conference, pp. 1-6, September 2011, Chicago, IL.

[11] S. Dusmez and A. Khaligh, "A novel low cost integrated on-board charger topology for electric vehicles and plug-in hybrid electric vehicles," in Proc., Applied Power Electronics Conference and Exposition, pp. 2611-2616, February 2012, Orlando, FL.

[12] SAE J2954 Standards Development for Wireless Charging of Electric and Plug-in Hybrid Vehicles, Standard development currently in progress, Available online: http://standards.sae.org/wip/j2954/

[13] O. C. Onar, J. M. Miller, S. L. Campbell, C. Coomer, C. P. White, and L. E. Seiber, "Oak Ridge National Laboratory wireless power transfer development for sustainable campus initiative," in Proc., IEEE Transportation Electrification Conference and Expo (ITEC), pp. 1-8, June 2013, Dearborn, MI.

[14] J. M. Miller and O. C. Onar, Short Course on Wireless Power Transfer (WPT) Systems, IEEE Transportation Electrification Conference and Expo (ITEC), June 2013, Dearborn, MI.

[15] M. S. Chinthavali, O. C. Onar, J. M. Miller, and L. Tang, "Single-phase active boost rectifier with power factor correction for wireless power transfer applications," in Proc., IEEE Energy Conversion Congress and Exposition, pp. 3258-3265, September 2013, Denver, CO. 